\title{
Experimental chemotherapy for Chagas disease: 15 years of research contributions from in vivo and in vitro studies
}

\author{
Maria de Nazaré C Soeiro, ${ }^{1,2}$, Andréia P Dantas², Anissa Daliry', Cristiane F da Silva1, \\ Denise GJ Batista', Elen M de Souza', Gabriel M Oliveira', Kelly Salomão', \\ Marcos Meuser Batista', Michelle GO Pacheco', Patrícia Bernardino da Silva', \\ Ricardo M Santa-Rita3 ${ }^{3}$ Rubem FS Menna Barreto , David W Boykin4, Solange Lisboa de Castro ${ }^{1 /+}$
}

\footnotetext{
${ }^{1}$ Laboratório de Biologia Celular, Instituto Oswaldo Cruz ²Programa Integrado de Doença de Chagas, Fiocruz, Av. Brasil 4365 , 21040-900 Rio de Janeiro, RJ, Brasil ${ }^{3}$ Campus Jataí, Universidade Federal de Goiás, Jataí, GO, Brasil ${ }^{4}$ Department of Chemistry, Georgia State University, Atlanta, Georgia, USA
}

Chagas disease, which is caused by the intracellular parasite Trypanosoma cruzi, is a neglected illness with 12-14 million reported cases in endemic geographic regions of Latin America. While the disease still represents an important public health problem in these affected areas, the available therapy, which was introduced more than four decades ago, is far from ideal due to its substantial toxicity, its limited effects on different parasite stocks, and its poor activity during the chronic phase of the disease. For the past 15 years, our group, in collaboration with research groups focused on medicinal chemistry, has been working on experimental chemotherapies for Chagas disease, investigating the biological activity, toxicity, selectivity and cellular targets of different classes of compounds on $\mathrm{T}$. cruzi. In this report, we present an overview of these in vitro and in vivo studies, focusing on the most promising classes of compounds with the aim of contributing to the current knowledge of the treatment of Chagas disease and aiding in the development of a new arsenal of candidates with anti-T. cruzi efficacy.

Key words: Trypanosoma cruzi - Chagas disease - experimental chemotherapy - aromatic diamidines - propolis $\mathrm{N}, \mathrm{N}$-dimethyl-propenamines - naphthoquinones

Chagas disease is a neglected illness caused by the intracellular obligatory parasite Trypanosoma cruzi, which is transmitted by haematophagous reduviid vectors. While it was described 100 years ago by Carlos Chagas (1909), this disease still represents an important health problem, and is broadly dispersed in 18 developing countries in South and Central Americas (Rocha et al. 2007). The overall prevalence of the disease is about 12-14 million cases, and its main clinical manifestations include cardiac and/or digestive alterations. In addition, Chagas disease is a major cause of cardiac infectious disease in endemic areas (Dias 2007, Anonymous 2006). Recently, Chagas disease has also been recognised as an opportunistic disease in HIV-infected individuals (Vaidian et al. 2004) and it is reported throughout the world due to international immigration (Schmunis 2007).

Chagas disease has two phases: the acute phase, which appears shortly after infection and whose symptoms range from flu-like symptoms to intense myocarditis (in about $10 \%$ of infected people) and the chronic symptomatic phase, which develops in about one-third of infected individuals following an asymptomatic period (indeter-

Financial support: CNPq, Faperj, Fiocruz, CAPES, PAPES V + Corresponding author: solange@ioc.fiocruz.br

Received 20 April 2009

Accepted 8 June 2009 minate form) of years or decades (Chagas 1909, Bilate $\&$ Cunha Neto 2008). While its pathology is still poorly understood, growing evidence has shown that parasite persistence within the target organs as a result of an unregulated host immune response is involved in pathogenesis, disease progression and outcome (Higuchi et al. 2003, Marino et al. 2005). In addition, despite fruitful efforts in the control of vectorial and blood transmission, Chagas disease still presents many challenges, including (i) its peculiar epidemiology, characterised by a variety of risk factors (many potential vectors and reservoirs, different forms of transmission and diverse parasite isolates present in domiciliar, peridomiciliar and sylvatic environments) and (ii) the lack of prophylactic therapies and effective chemotherapeutic schemes (Coura \& De Castro 2002, Coura 2007, Dias 2007). Nifurtimox (Nf) and benznidazole $(\mathrm{Bz})$ are the drugs that are available for the treatment of chagasic patients. However, due to their well-known toxicity and limited effect towards different parasite isolates and disease phases (primarily patients in the later chronic phase), new drugs are urgently needed (Coura \& De Castro 2002, Soeiro \& De Castro 2009). While many trypanocidal compounds have been screened in the past few decades and some promising targets have been reported since the introduction of $\mathrm{Nf}$ and $\mathrm{Bz}$ (1960-1970), only allopurinol and a limited number of azoles, such as itraconazole, fluconazole and ketoconazole have moved to clinical trials (Brener et al. 1993, Solari et al. 1993, Apt et al. 2005). This situation may reflect (i) low investments in this area, primarily by the pharmaceutical industry, (ii) the misconception 
that during the later stages of the disease the parasite is absent and thus does not correlate with disease outcome and pathogenesis, and (iii) the lack of standardised protocols for drug screening. Thus, based on the current knowledge of parasite and host biology, an ideal drug candidate for Chagas disease would have the following characteristics: (i) a high level of activity against the evolutive forms present in mammalian hosts and against different stocks of the parasite; (ii) efficacy against both acute and chronic infections; (iii) oral administration in few doses; (iv) low toxicity and improved safety (including in children and women of reproductive age); (v) low cost and high stability for a long shelf life in tropical temperatures and (vi) high levels of tissue accumulation and long terminal half lives (Nwaka \& Hudson 2006).

In this context, an overall discussion is provided on the main advances made over the last 15 years from in vitro and in vivo studies related to anti-T. cruzi candidates screened at the Laboratório de Biologia Celular of the Instituto Oswaldo Cruz/Fiocruz in collaboration with different groups working in medicinal chemistry, including those headed by Drs. David W. Boykin (Georgia State University, USA), Richard Tidwell (University of North Carolina, USA), Nelson Duran (Unicamp, Brazil) and Antonio Ventura Pinto (UFRJ, Brazil). However, additional pharmacological and safety tests are needed in subsequent studies to identify and move promising compounds to clinical trials.

\section{Diamidines and related compounds}

Diamidine-containing compounds such as pentamidine, propamidine and diminazene aceturate (also known as Berenil, a drug commonly used against trypanosome infections in livestock) are DNA minor groove binders that have long been used in infectious disease chemotherapy.

Pentamidine, employed for over 60 years against early-stage human African trypanosomiasis, is also used to treat cutaneous leishmaniasis caused by Leishmania guyanensis and antimony-resistant visceral cases (Blum et al. 2004, Oliaro et al. 2005, Werbovetz 2006).

However, while presenting such a high potency, pentamidine, as well as some other diamidines such as furamidine (DB75), display poor oral bioavailability and unfavorable side effects. In order to overcome these limitations, the synthesis and screening of new dications and their prodrugs have been performed (Werbovetz 2006). One such orally effective prodrug, DB75 (DB 89), was in Phase III clinical trials for the treatment of human African trypanosomiasis. Despite initial indications of low toxicity in African, Asian, Caucasian and Hispanic populations (Soeiro et al. 2008), recent results from studies using extended dosages led to a withdrawal of DB289 from further human trials.

While these dicationic compounds have been studied primarily against African trypanosomes, few have been assayed as anti-T. cruzi candidates (Wilson et al. 2008). In the past few years, our laboratory has been working on the anti-T. cruzi activity of novel dications using both in vitro and in vivo experimental models. The aim of this work has been to select and evaluate the effectiveness of furamidine analogues of different shapes, cationic centres and effective motifs as well as to test the assumed requirement of the dications. Our data clearly show a number of very promising candidates that display high therapeutic windows (De Souza et al. 2004, 2006a, b, 2007, Silva et al. 2007a, b, 2008). As a result of collaboration with the Drs. D. Boykin (Georgia State University, USA) and R. Tidwell (University of North Carolina, USA), we have obtained very exciting findings as both research groups have a large amount of experience with the molecules and a collective expertise in both anti-parasitic drug discovery and development on different parasitic infections.

Our data show that while furamidine and its Nphenyl substituted analogue (DB569) (Figure) display equivalent DNA binding properties, DB569 exhibited higher in vitro activity against different strains and stages of the parasite, displaying inhibitory values in the low-micromolar range. Due to the characteristic fluorescence of these compounds, it was possible to localise both in DNA enriched organelles, with kDNA being strongly labelled (De Souza et al. 2004, Soeiro et al. 2005). Importantly, flow cytometry and transmission electron microscopy (TEM) analysis have also demonstrated that both drugs disturb parasite mitochondria and nuclei, leading to morphological characteristics of programmed cell death, with DB569 achieving higher levels of apoptotic-like parasites (De Souza et al. 2004, 2006b). These findings stimulated further in vivo analysis with DB569, which reduced cardiac parasite load and down-modulated the expression of $\mathrm{CD} 8^{+} \mathrm{T}$ cells in the heart tissues (De Souza et al. 2006a, 2007). DB569 also revert the electrocardiography (ECG) alterations in acutely treated $T$. cruzi-infected mice compared to those in untreated animals, leading to an increase in the survival rates of the former group (De Souza et al. 2007). The ECG protection provided by DB569 was also found during the chronic infection phase of experimental animals suggesting that the reversion to and the further maintenance of a normal ECG profile in the DB569treated animals may be associated with reduced cardiac $\mathrm{CD}^{+}$lymphocyte infiltration and parasitism (De Souza et al. 2006a, 2007).

Another study performed with a diarylthiophene diamidine (DB1362) (Figure) against both amastigotes and bloodstream trypomastigotes of $T$. cruzi showed good in vitro efficacy at submicromolar $\mathrm{IC}_{50}$ doses that did not induce host cytotoxicity (Silva et al. 2008). We also found a dose-dependent trypanocidal effect after $24 \mathrm{~h}$ of incubation in the presence of plasma constituents (mice blood), exhibiting similar $\mathrm{IC}_{50}$ values as those found in the absence of blood. This result argues for the possible application of blood banks in prophylactic treatment. Analysis of bloodstream parasites by TEM and flow cytometry confirmed that the most important alterations correlated to kinetoplast organisation and mitochondrial membrane potential (Silva et al. 2008). In view of the in vitro trypanocidal effect, we performed further in vivo studies in an acute $T$. cruzi-experimental mice model (male Swiss mice infected with the Y strain) us- 
<smiles>N=C(N)c1ccc(-c2ccc(-c3ccc(C(=N)N)cc3)o2)cc1</smiles>

(a)<smiles>N=C(Nc1ccccc1)c1ccc(-c2ccc(-c3ccc(C(=N)Nc4ccccc4)cc3)o2)cc1</smiles><smiles>O=C(Nc1ccc(-c2ccc(-c3ccc(NC(=O)c4ccccc4)cc3)o2)cc1)c1ccccc1</smiles>

(c)

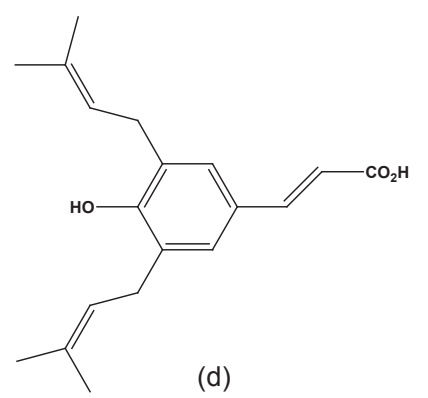

(d)<smiles>CC1(C)CCc2c(c3ccccc3c3nc(-c4c[nH]c5ccccc45)[nH]c23)O1</smiles>

(h)

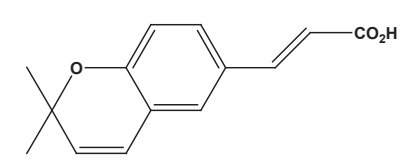

(e)

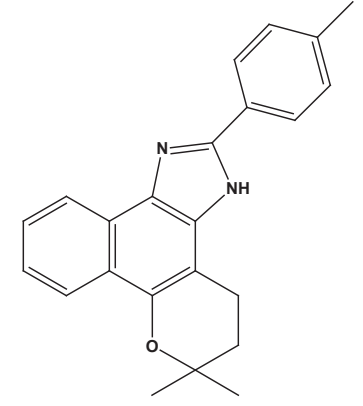

(i)

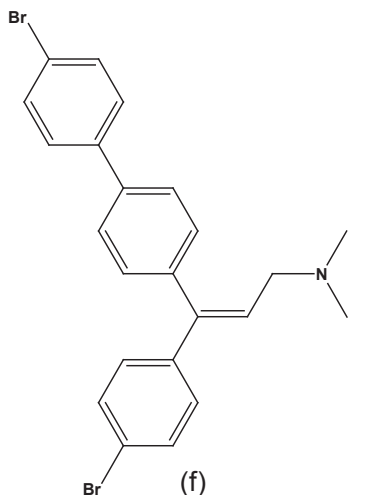<smiles>CC1(C)CCc2c(c3ccccc3c3nc(-c4ccccc4)[nH]c23)O1</smiles>

(g)

Chemical structures: a: furamidine; b: DB569; c: DB613A; d: 3,5-diprenyl-4-hydroxycinnamic acid derivative; e: 2,2-dimethyl-6-carboxyethenyl-2H-1-benzopyran; f: 3-[4'-bromo-(1,1'-biphenyl)-4-yl]-N,N-dimethyl-3-(4-bromo-phenyl)-2-propen-1-amine; g: 4,5-dihydro-6,6-dimethyl$6 \mathrm{H}-2$-(phenyl)-pyran[b-4,3]naphth[1,2-d]imidazole); h: 4,5-dihydro-6,6-dimethyl-6H-2-(3'-indolyl)-pyran[b-4,3]naphth[1,2-d] imidazole; i: 4,5-dihydro-6,6-dimethyl-6H-2-(4'-methylphenyl)-pyran[b-4,3]naphth[1,2-d]imidazole).

ing a two or a 10-day regime at doses that did not did not exert substantial side effects in treated animals. In parallel, we used a mouse group that received $\mathrm{Bz}(100 \mathrm{mg} /$ $\mathrm{kg}$ by gavage) as the reference drug. Our findings show that the best results were obtained when the mice were treated with $25 \mathrm{mg} / \mathrm{kg}$ of DB1362 administrated at two intervals ( 1 at the onset and the 2 nd at the parasitemia peak). While we found only a reduction of about $40 \%$ in the circulating parasitemia levels, the treatment induced $100 \%$ survival, which was largely due to reduced cardiac parasitism (similar levels as Bz) in addition to protecting against cardiac electric alterations due to the parasite infection (Silva et al. 2008).

In a recent unpublished study, the biological, ultrastructural effect and subcellular localisation of six diamidines was studied in T. cruzi (Batista et al. 2009). The 
data confirmed the low toxicity of these diamidine compounds towards mammalian cells $\left(\mathrm{LC}_{50}>96 \mu \mathrm{M}\right)$. Additionally, the three dicationic compounds, with the exception of the smaller linear molecules (DB1627, DB1646 and DB1670), which were not effective, exerted a very high efficacy against both relevant forms of the parasite that are present in mammalian hosts, with $\mathrm{IC}_{50}$ values ranging from 0.15-13.3 $\mu \mathrm{M}$ (DGJ Batista et al., unpublished observations). While several potential transporters that effectively carry diamidines have been studied in other parasites, including African trypanosomes, Leishmania species and Plasmodium falciparum (Carter et al. 1995, Barret et al. 2003, Bray et al. 2003), the mechanism of uptake of diamidines by $T$. cruzi remains unknown and deserves further investigation. However, due to the intrinsic fluorescent characteristics of these compounds, it is possible to follow their distribution in $T$. cruzi as was previously performed with African trypanosomes (Mathis et al. 2006, 2007, Wilson et al. 2008). We found that in addition to the known localisation of these compounds in the parasite nuclei and kDNA (with a greater intensity displayed in the later structure), two of the compounds (DB1582 and DB1651) were found within punctate, non-DNA-containing, cytoplasmic organelles. These organelles were preferentially localised in the anterior portion of bloodstream trypomastigotes and near the nuclei and kinetoplast regions of amastigotes and therefore, are possibly acidocalcisomes, which has been previously reported for Trypanosoma brucei (Mathis et al. 2006). As suggested for African trypanosomes, the localisation of these compounds within these acidic organelles could play a role in their mechanism of action; these organelles may also act as storage sites (Mathis et al. 2006, 2007) and additional studies are necessary to clear this matter. In the study by DGJ Batista et al. (unpublished observations) we also provided additional TEM data confirming that these diamidines caused striking alterations in the mitochondria and kinetoplast of the parasites. In addition, the compounds also induced disorganisation of microtubules leading to the formation of multiple axoneme structures in diamidine-treated bloodstream forms (Silva et al. 2007a, DGJ Batista, unpublished observations). To date, no major alterations have been reported in both sub-pellicular and flagellar microtubules of $T$. cruzi treated with microtubule-targeting drugs such as taxol, colchicine and vinblastine. This may be a consequence of the high content of acetylated tubulin and/or poly-glutamylation of tubulin that is present in these parasites (Souto-Padron et al. 1993, Dantas et al. 2003). Since these structures in trypanosomatids are very resistant to microtubule disrupters compared to the microtubule structures in mammalian cells, they may represent interesting targets for drug development and deserve further investigation.

In fact, the mechanism of action of diamidines and related compounds has not been fully elucidated and multiple modes of action have been proposed (Wilson et al. 2008). One of the long-hypothesised mechanisms of action of diamidines is their ability to bind to AT-rich regions of the DNA minor groove but other mechanisms such as inhibition of tyrosyl-DNA phosphodiesterase, topoisomerases, protein kinase A, proteases and polymerases have been suggested (Shapiro \& Englund 1990, Dykstra et al. 1994, Soeiro et al. 2008). As the kDNA of kinetoplastid parasites possesses a high number of adenosine and thymine (AT) binding sites in thousands of repeated minicircles, these structures may represent potential cellular targets for diamidine and related compounds that have AT sequence binding specificity (Wilson et al. 2008). However, while diamidines are excellent minor groove DNA binders, this interaction itself cannot fully explain their biological activity. Recent reports suggest that their association with DNA is an initial step and that it is followed by topological changes that lead to molecule instability and destruction and/or modification of DNA-protein interactions; this, in turn leads to replication errors, DNA degradation and eventual parasite death (Singh \& Dey 2007, Wilson et al. 2008). Interestingly, recent unpublished results from our group from the screening of 21 dicationic molecules against $T$. cruzi showed that while all compounds were localised to a greater extent within the kinetoplast than in the nucleus, no correlation could be found between compound activity and the level of kDNA accumulation (A Daliry et al., unpublished observations, CF Silva et al., unpublished observations). These results are consistent with previous data from T. brucei (Mathis et al. 2006).

Arylimidamides, previously known as reversed amidines, have extraordinary activity against both Leishmania (Stephens et al. 2003, Rosypal et al. 2007, 2008) and T. cruzi (Silva et al. 2007a, b, Pacheco et al. 2009, unpublished observations). They differ form other furan analogs because the amidine is bound to the central aromatic linker via a nitrogen atom rather than a carbon atom (Rosypal et al. 2008). In a recent study, the analysis of arylimidamides on promastigotes and amastigotes of Leishmania showed that most compounds (9 out of 10) from this class display a 250 -fold and a 4.5 -fold greater activity that pentamidine (Rosypal et al. 2008).

According to the T. cruzi data, we have demonstrated their potent in vitro dose-dependent activity $\left(\mathrm{IC}_{50}\right.$ in the low-micromolar range), showing superior trypanocidal activity compared to diguanidino cationic groups (Silva et al. 2007a). TEM and flow cytometry data also showed primarily mitochondrial alterations in the amidine treated parasites (Silva et al. 2006).

In another recent study we reported the in vitro trypanocidal effect of several different heterocyclic cationic compounds, including diamidines, a monoamidine, an arylimidamide and a guanylhydrazone and found that all compounds exerted, at low micromolar doses and to various extents, a trypanocidal effect on both intracellular parasites and bloodstream trypomastigotes (Pacheco et al. 2009, unpublished observations). However, the potency and selectivity of DB613A, an arylimidamide (Figure), towards intracellular parasites (reaching a selective index of $>126$ ), corroborates previous results that demonstrated the high activity of this class of compounds against this parasite. These results therefore justify further studies on experimental models of $T$. cruzi infection. 


\section{Propolis}

Propolis is a product from bees that is extensively used in folk medicine for a wide spectrum of diseases (Bankova et al. 2000). Our laboratory is, and has been for several years, involved in the investigation of the trypanocidal effect of propolis (Higashi \& De Castro 1994, De Castro \& Higashi 1995, Cunha et al. 2004). This resinous material is collected from different plant exudates and presents a complex composition that is dependent on the plant sources accessible to the bees (De Castro 2001). In temperate zones, poplar trees (Populus spp.) are the main source of propolis, and its biological activity has been associated to the presence of flavonoids and caffeic acid derivatives (Hegazi et al. 2000, Prytzyk et al. 2003). In tropical regions, a variety of plant sources exist, which results in a number of samples with distinct compositions, a characteristic that is dependent on the local flora at the site of collection (Marcucci et al. 2001, Park et al. 2002, Trusheva et al. 2006).

Brazilian propolis has been the subject of intensive research over the past few decades and has been subdivided into four types based on the association of ethanol extracts of Brazilian samples with the levels of specific compounds (Marcucci 2000). In collaboration with Dr. Maria Cristina Marcucci (Uniban, São Paulo), who determined the composition of standardised ethanol extracts from Brazilian samples by high-performance liquid chromatography (Marcucci et al. 2001), we investigated the correlation between the presence of bioactive components with the activity against bloodstream trypomastigotes. Based on the predominant botanical origin in the region from which the samples were collected, the 10 extracts were separated into three groups: A (Baccharis dracunculifolia + Araucaria spp), B (B. dracunculifolia) and C (Araucaria spp). Analysis by multiple regression of all the extracts performed by Dr. Pedro Cabello (Fiocruz) showed a positive correlation with samples containing a higher concentration of the 3,5diprenyl-4-hydroxycinnamic acid derivative 4 (DHCA4) and 2,2-dimethyl-6-carboxyethenyl-2H-1-benzopyran (DCBEN) having a higher trypanocidal effect (Figure). Reliable statistical analysis on each of the three groups was not possible due to the small numbers of observations. However, an overall analysis revealed an association of anti-T. cruzi activity with dicaffeoylquinic acid 3 in group A and with caffeic acid in group B. No association was observed between the trypanocidal effect and any component of the extracts in group $\mathrm{C}$. The present study reinforces the relevance of para-coumaric acid and its derivatives, particularly the prenylated and caffeolyquinic acid forms, on the biological activity of Brazilian propolis (Salomão et al. 2008).

In another line of research, we compared the activity and mode of action of propolis from temperate and tropical regions by determining the compositions and investigating the effects against $T$. cruzi of standard ethanolic extracts from a Bulgarian (Et-Blg) and a Brazilian sample (Et-Bra). Et-Blg possessed a high content of flavonoids and was active on epimastigotes and trypomastigotes. In the presence of blood, the activity of Et-Blg was similar to that of the standard drug crystal violet. A methanolic extract of the same sample displayed low activity on trypomastigotes, which was associated with a high concentration of mono and disaccharides and therefore resulting in a low concentration of potentially active compounds (Paulino et al. 2003, Prytzyk et al. 2003). The treatment of T. cruzi-infected skeletal muscle cells with Et-Blg led to a decrease of infection and an inhibition of intracellular proliferation of amastigotes with no toxicity to the host cell. Ultrastructural analysis revealed the mitochondrion and reservosomes to be the main targets of the extract in epimastigotes, while in trypomastigotes the mitochondrion-kinetoplast complex was the most susceptible structure (Dantas et al. 2006). In experimentally infected mice, treatment with $50 \mathrm{mg}$ Et-Blg/ $\mathrm{kg}$ body weight/day led to a decrease in parasitemia with no hepatic or renal toxic effect. Additionally, the extract induced a decrease in spleen mass and interfered with the basic properties of immune cells (Dantas et al. 2005). Et-Bra was obtained from a sample of Brazilian green propolis that was classified as a BRP1 (Marcucci 2000) because of the high content of the bioactive compounds DHCA, 2,2-dimethyl-8-prenyl-2H-1benzopyran-6-propenoic acid, 3-prenyl-4-hydroxycinnamic acid, para-coumaric acid as well as the absence of DCBEN (Salomão et al. 2004). Data obtained from ultrastructural and flow cytometry analysis indicated that Et-Bra induced plasma membrane damage in trypomastigotes, reservosomes disorganisation and mitochondrial swelling in epimastigotes. Acutely infected mice were treated orally with Et-Bra and the parasitemia, mortality and GPT, GOT, CK and urea levels were monitored. The extract (25-300 mg/kg body weight/day for 10 days) reduced parasitemia, though not to significant levels; the extract also increased the survival of the animals and did not induce any hepatic, muscular lesion or renal toxicity. Since Et-Bra was not toxic to the animals, it could be assayed in combination with other drugs (Salomão et al. 2009, unpublished observations). While the results obtained with different samples all had established chemical compositions, the intrinsic complex characteristic of propolis and the in vivo results does not present propolis as an ideal trypanocidal agent for further investigation. However, since propolis from both temperate and tropical zones is active on different species of Leishmania (Machado et al. 2007), studies about the in vivo topical treatment of new formulations need to be performed in cutaneous models of leishmaniasis.

\section{$\mathbf{N}, \mathbf{N}$-dimethyl-2-propen-1-amine derivatives}

In collaboration with Dr. N. Duran (IQ/Unicamp) we developed a series of 3-[4'-bromo-(1,1'-biphenyl)-4-yl]N,N-dimethyl-3-(4-X-phenyl)-2-propen-1-amine derivatives ( $\mathrm{X}=\mathrm{H}, \mathrm{OMe}, \mathrm{NO}_{2}, \mathrm{Me}, \mathrm{SO}_{3} \mathrm{H}, \mathrm{Br}$, I and thienyl) and assayed their in vitro activity against $T$. cruzi. These compounds are characterised by the para-substitution on the phenyl moiety and were obtained as an isomeric mixture of $Z$ :E (nearly 1:1) with high purity and good yields. These compounds can easily penetrate the plasma membrane and accumulate in the lysosomes, where they become trapped in the protonised form as a result 
of the acid environment inside this organelle (Lüllmann et al. 1978). Barrett et al. (1982) have previously reported that the chloro derivative $(\mathrm{X}=\mathrm{Cl})$ tested as an $\mathrm{E}$ isomer salt is highly effective in suppressing mice infections induced by different stocks of $T$. cruzi and is more active than either $\mathrm{Nf}$ or $\mathrm{Bz}$.

$\mathrm{The} \mathrm{IC}_{50} / 24 \mathrm{~h}$ values for the proliferative amastigote and epimastigote forms were in the range of 5-25 $\mu \mathrm{M}$, while for trypomastigotes it was between $12-55 \mu \mathrm{M}$, which is in the same range as $\mathrm{Nf}$ (De Conti et al. 1996a, b, 1998, Souza et al. 2002, 2004). The unsubstituted and the chloro derivatives were the more active agents against all three forms of the parasite. The activity of the cis and trans isomers of both the unsubstituted and the bromo derivatives were evaluated, with the former being the most active on bloodstream trypomastigotes (Oliveira et al. 2005). The chromatographic analysis of epimastigotes treated with the unsubstituted 2-propen-1amine showed a decrease in the ergosterol levels and an increase in the concentration of squalene. The 2-propen1 -amines can act to reduce the conversion of squalene to squalene epoxide, a reaction that is catalysed by squalene epoxidase. This enzymatic step is a target of allylamines in fungi and protozoa and represents an interesting target to be explored in drug discovery.

In experimentally infected mice, while the unsubstituted analogue $(\mathrm{X}=\mathrm{H})$ was ineffective, the corresponding bromo derivative $(\mathrm{X}=\mathrm{Br})$ (Figure) was very active. At a regimen of $5 \mathrm{mg} / \mathrm{kg}$ for nine consecutive days, the latter led to a consistent suppression of parasitemia combined with full protection against death at levels comparable to the treatment with $\mathrm{Bz}$ at $100 \mathrm{mg} / \mathrm{kg}$ (Pereira et al. 1998, Oliveira et al. 2005). This class of compounds deserves further investigation based on the excellent in vivo results obtained.

\section{Naphthoquinones and derivatives}

Naphthoquinones are compounds that are present in various families of plants; their molecular structures endow them with redox properties and therefore, they participate in different biological oxidative processes. In folk medicine and particularly among Indian populations, plants containing naphthoquinones have been employed for the treatment of different diseases such as cancer (Arenas 1987, Bastien et al. 1983). The biological redox cycle of quinones can be initiated by one electron reduction leading to the formation of semiquinones, unstable intermediates that react rapidly with molecular oxygen to generate free radicals. An alternative pathway is the reduction by two electrons, mediated by DTdiphorase, leading to the formation of hydroquinone. Lapachol, $\beta$-lapachone and $\alpha$-lapachone isolated from the heartwood of trees of the Bignoniaceae family that are abundant in tropical rain forests. In Brazil, more than 46 types of such woods, popularly known by the name of ipes (Tabebuia sp.), have been described. These compounds act as inhibitors of electron transport, uncouplers of oxidative phosphorylation, DNA intercalating agents and as producers of reactive oxygen radicals $\left(\mathrm{O}^{\prime}\right.$ Brien 1991, Monks et al. 1992, Goulart et al. 2003). The activity of lapachol, $\beta$-lapachone and derivatives on viruses,
Schistosoma mansoni and the pathogenic protozoan Leishmania sp, Toxoplasma gondii and P. falciparum has been examined (Pinto et al. 2007). Due to the easy access to natural sources of quinones from the Brazilian flora and the synthetic alternative routes previously developed by the group of Dr. Ventura Pinto (NPPN/UFRJ) (who are exploring the electrophilicity of 1,2-quinoidal carbonyls with reagents presenting heteroatom nucleophilic centres) (Pinto et al. 1982, 1985, 1997a, Lopes et al. 1984, Chaves et al. 1990), naphthoquinones were used as starting points in medicinal chemistry studies.

Since the 90 's we have been studying the anti- $T$. cruzi activity of this class of chemicals (De Castro et al. 1994). We screened 54 derivatives obtained by Dr. Ventura Pinto through the reaction of naphthoquinones with common reagents used in heterocyclic chemistry. This has led to the synthesis of 14 oxazolic, 30 imidazolic and 10 additional heterocyclic compounds, including a phenoxazine, a dihydro indol, six cyclopentenic and two pyranic. The analysis of these compounds, together with those of the original 9-naphthoquinones [lapachol, $\beta$-lapachone, $\alpha$-lapachone, nor- $\beta$-lapachone, nor-lapachol, methoxy- $\beta$-lapachol, lawsone, O-allyl lawsone and $\mathrm{C}$-allyl lawsone], were performed using infective bloodstream forms of the parasite that were treated for $24 \mathrm{~h}$ at $4{ }^{\circ} \mathrm{C}$ in culture medium in the presence of $5 \%$ blood and using the $\mathrm{IC}_{50}$ value as the parameter as previously described (De Castro et al. 1994).

In comparing the activities of the original naphthoquinones, we concluded that minor structural features involved in increases in lipophilicity, such as the furane moiety or the presence of a methoxyl group or an aliphatic side chain led to an increase in the effect against $T$. cruzi. It is possible that a lipophylic character allows for better penetration of the compound through the plasma membrane of the parasite. The activity of the synthesised compounds against $T$. cruzi showed no uniform behaviour, at times showing higher, lower or similar activities to those of the original naphtoquinones from which they were obtained. For the naphthooxazoles assayed, there was no correlation between biological activity and the type of mono-oxygenated ring (pyrane vs. furane). As previously discussed for napthaquinones, the lipophylic character introduced by this appendage, as well as the presence of a methoxyl or a phenyl group, are factors that increase the trypanocidal activity. A characteristic of the synthesised naphthoimidazoles is that most of them present aromatic groups containing electron-releasing or electron-withdrawing groups attached to the imidazole ring (Pinto et al. 1997b, Neves-Pinto et al. 2000, 2002, Moura et al. 2001, 2004). The results suggested that electronic factors related to the phenyl group were not relevant for the biological effect. Among the investigated compounds, three naphthoimidazoles derived from $\beta$-lapachone and containing the aromatic moieties phenyl (N1), 3-indolyl (N2) and methyl-p-phenyl (N3) (Figure) showed the highest activity against the parasite and were selected for further studies on their activity on intracellular amastigote forms and their toxicity to mammalian cells (Menna-Barreto et al. 2005, 2007, 2009a). As mode of action of naphthoimidazoles on the parasite, 
we can exclude damage caused by oxidative stress since unlike the original napthoquinones, these derivatives do not easily undergo redox reactions. It is important to note that several trypanocidal agents, such as Bz, contain basic imidazolic moieties (Winkelman et al. 1978, McCabe et al. 1983, Chabala et al. 1991, Nothenberg et al. 1991, Blandon et al. 1993, Sepulveda-Boza \& Cassels 1996), which is consistent with the idea that trypanocidal activity is associated with the imidazolic skeleton.

The three naphthoimidazoles were active on trypomastigotes, intracellular amastigotes and epimastigotes, and presented low toxicity to the host cell. In epimastigotes, the compounds blocked the cell cycle, inhibited succinate cytochrome $\mathrm{c}$ reductase, metacyclogenesis and induced damage to the mitochondrion, Golgi complex and reservosomes. In treated trypomastigotes, alterations occurred in the kinetoplast, mitochondrion and induced plasma membrane blebbing and DNA fragmentation (Menna-Barreto et al. 2005, 2007). Investigation into their mode of action led to the identification of the mitochondrion, reservosomes and DNA as their main targets, and stimulated further studies on the death pathways. Ultrastructural analysis revealed both authophagic (autophagosomes) and apoptotic-like (membrane blebbing) phenotypes. Flow cytometry analysis showed that in N1 or N2-treated trypomastigotes, a small increase in phosphatidylserine exposure and a large increase in the percentage of necrosis were observed. These death phenotypes were not detected in treated epimastigotes. The strong increase in labelling of monodansyl cadaverine, the inhibition of the death process by wortmannin or 3-methyladenine, the overexpression of the $A T G$ genes in treated epimastigotes, as well as the ultrastructural evidence point to autophagy as being the predominant phenotype induced by the naphthoimidazoles (MennaBarreto et al. 2007, 2009a, c).

In another approach, new compounds were also prepared through molecular hybridisation. Exploring the electrophilicity of 1,2-quinoidal carbonyls, naphthoquinones were coupled to $[1,2,3]$-triazoles or arylamines resulting in a series of derivatives that were also assayed on bloodstream trypomastigotes. Substituted ortho-naphthofuranquinones (a non-substituted paranaphthofuranquinone), a new oxyrane and an azide were prepared from nor-lapachol while a new non-substituted para-naphthofuranquinone was prepared from $\alpha$-lapachone. The most active compounds were three ortho naphthofuranquinones with trypanocidal activity higher than that of $\mathrm{Bz}$, the standard drug (Silva et al. 2008b). The $[1,2,3]$-triazole derivatives of nor- $\beta$ lapachone were more active than the original quinones, with the apolar phenyl substituted triazole derivative being the most active compound (Silva et al. 2008a). Such hybrid molecules obtained from quinones plus a triazole or arylamino group endowed the quinines with redox properties. These strategies represent an interesting starting point for a medicinal chemistry program that is focused on the chemotherapy of Chagas disease.

Three new naphthofuranquinones were synthesised and assayed against $T$. cruzi. Two derivatives were obtained by the addition of iodine to C-allyl-lawsone (2-hydroxy-3-allyl-naphthoquinone), followed by cyclisation to generate a furan ring; a third compound was obtained through an acid-catalysed reaction by dissolution of the original quinone in sulfuric acid. These compounds were active against the trypomastigote, intracellular amastigote and epimastigote forms presented low toxicity toward host mammalian cells and their chemical structure endowed them with redox properties, thus stimulating further studies (Silva et al. 2006). Ultrastructural analysis of treated epimastigotes and trypomastigotes indicated potent effects of the three naphthofuranquinones in parasite mitochondria, which appeared drastically swollen and possessed a washedout matrix profile. Fluorescence-activated cell sorting analysis of rhodamine 123 -stained T. cruzi showed that they caused a potent dose-dependent collapse of mitochondrial membrane potential, especially in epimastigote forms. These compounds also specifically decreased mitochondrial complex I-III activities in both epimastigotes and trypomastigotes, which parallel the reduction in succinate-induced oxygen consumption. Mitochondrial hydrogen peroxide formation was also increased in epimastigotes after treatment with naphthofuranquinones. Our results indicate that the trypanocidal actions of the naphthofuranquinones are associated with mitochondrial dysfunction, leading to increased reactive oxygen species generation and parasite death (Menna-Barreto et al. $2009 \mathrm{~b}$, unpublished observations). The tractable synthesis route of these compounds in the laboratory opens the possibility for large-scale production with high yields that can be assayed in experimental mouse models.

In conclusion, a number of factors limit the utility of the existing drugs for Chagas disease primarily because of their low efficacy (mostly upon chronic patients), poor activity against many T. cruzi isolates circulating in different geographic areas and considerable side effects. Additionally, in the past few decades, few compounds have moved to clinical trials due to the minimal investments allocated in this area (as well as to other neglected diseases) and the lack of standardised protocols for drug screening. In addition, the identification of new trypanocidal candidates that could enter clinical studies requires integrated partnerships and interdisciplinary networks that involve expertise in a variety of fields such as molecular and cellular biology, chemistry and biochemistry, pharmacology and toxicology. Thus, with the advent of genomics, rapid DNA sequencing, bioinformatics, proteomics, combinatorial chemistry and automated highthroughput screening, extensive knowledge has be accumulated that provides new insight toward the discovery of more selective and successful compounds that could be applied to Chagas disease therapy.

\section{REFERENCES}

Anonymous 2006. Chagas' disease - an epidemic that can no longer be ignored. Lancet 368: 619 .

Apt W, Arribada A, Zulantay I, Solari A, Sánchez G, Mundaca K, Coronado X, Rodríguez J, Gil LC, Osuna A 2005. Itraconazole or allopurinol in the treatment of chronic American trypanosomiasis: the results of clinical and parasitological examinations 11 years post-treatment. Ann Trop Med Parasitol 99: 733-741. 
Arenas P 1987. Medicine and magic among the Maka Indians of the Paraguayan Chaco. J Ethnopharmacol 21: 279-295.

Bankova VS, De Castro SL, Marcucci MC 2000. Propolis: recent advances in research on chemistry and plant origin. Apidologie 31: 3-15.

Barrett MP, Burchmore RJ, Stich A, Lazzari JO, Frasch AC, Cazzulo JJ, Krishna S 2003. The trypanosomiases. Lancet 362: 1469-1480.

Barrett PA, Beveridge E, Bull D, Caldwell IC, Islip PJ, Neal RA, Woods NC 1982. The efficacy of a novel compound, (E)-1-(4'-bromo-4biphenylyl)-1-(4-chlorophenyl)-3-dimethylaminoprop-1-ene against Trypanosoma cruzi in mice. Experientia 38: 338-339.

Bastien JW 1983. Pharmacopeia of Qollahuaya Andeans. J Ethnopharmacol 8: 97-111.

Bilate AM, Cunha-Neto E 2008. Chagas disease cardiomyopathy: current concepts of an old disease. Rev Inst Med Trop Sao Paulo 50: $67-74$.

Blandon R, Johnson CM, Sousa O, Leandro I, Guevara JF 1993. The clinical experience in Panama with metronidazole in treating Chagas' disease in the acute and chronic phases. Rev Med Panama 18: 94-100.

Blum J, Desjeux P, Schwartz E, Beck B, Hatz C 2004. Treatment of cutaneous leishmaniasis among travelers. J Antimicrob Chemother 53: 158-166.

Bray PG, Barrett MP, Ward SA, de Koning HP 2003. Pentamidine uptake and resistance in pathogenic protozoa: past, present and future. Trends Parasitol 19: 232-239.

Brener Z, Cançado JR, Galvão LM, Da Luz ZM, Filardi LS, Pereira ME, Santos LM, Cançado CB 1993. An experimental and clinical assay with ketoconazole in the treatment of Chagas disease. Mem Inst Oswaldo Cruz 88: 149-153.

Carter NS, Berger BJ, Fairlamb AH 1995. Uptake of diamidine drugs by the $\mathrm{P} 2$ nucleoside transporter in melarsen-sensitive and -resistant Trypanosoma brucei brucei. J Biol Chem 270: 28153-28157.

Chabala JC, WQaits VB, Ikeler T, Patchett AA, Payne L, Peterson LH, Reamer RA, Hoogsteen K, Wyvratt M, Hanson WL, Fisher MH 1991. 1-(substituted)benzyl-5-aminiimidazole-4-carboxamides are potent orally active inhibitors of Trypanosoma cruzi in mice. Experientia 47: 51-53.

Chagas C 1909. Nova tripanosomíase humana - Estudos sobre a morfologia e o ciclo evolutivo de Schizotrypanum cruzi gen. nov. sp. nov., agente etiológico de nova entidade mórbida do homem. Mem Inst Oswaldo Cruz 1: 159-218.

Chaves JP, Pinto MCFR, Pinto AV 1990. Heterocyclics from quinones. I - Reaction of lapachol with primary alkyl amines. J Braz Chem Soc 1: 21-27.

Coura JR 2007. Chagas disease: what is known and what is needed - A background article. Mem Inst Oswaldo Cruz 102: 113-122.

Coura JR, De Castro SL 2002. A critical review on Chagas disease chemotherapy. Mem Inst Oswaldo Cruz 97: 3-24.

Cunha IBS, Salomão K, Shimizu M, Bankova VS, Custódio AR, De Castro SL, Marcucci MC 2004. Anti-trypanosomal activity of Brazilian propolis from Apis mellifera. Chem Pharm Bull 52: 602-604.

Dantas AP, Barbosa HS, De Castro SL 2003. Biological and ultrastructural effects of the anti-microtubule agent taxol against Trypanosoma cruzi. J Submicr Cytol Pathol 35: 287-294.

Dantas AP, Olivieri BP, Gomes FHM, De Castro SL 2005. Treatment of Trypanosoma cruzi-infected mice with propolis promotes changes in the immune response. J Ethnopharmacol 103: 187-193.
Dantas AP, Salomão K, Barbosa HS, De Castro SL 2006. The effect of Bulgarian propolis against Trypanosoma cruzi. Mem Inst Oswaldo Cruz 101: 207-211.

De Castro SL 2001. Propolis: biological and pharmacological activities. Therapeutic uses of this bee-product. Ann Rev Biol Sci 3: 49-83.

De Castro SL, Higashi KO 1995. Effect of different formulations of propolis on mice infected with Trypanosoma cruzi.J Ethnopharmacol 46: 55-59.

De Castro SL, Pinto MCFR, Pinto AV 1994. Screening of natural and synthetic drugs against Trypanosoma cruzi. 1 - Establishing a structure/activity relationship. Microbios 78: 83-90.

De Conti R, Gimenez SMN, Haun M, Pilli RA, De Castro SL, Durán N 1996a. Synthesis and biological activities of N,N-dimethyl-2propen-1-amine derivatives. Eur J Med Chem 31: 915-918.

De Conti R, Oliveira DA, Fernandes AMAP, Melo PS, Rodriguez JA, Haun M, De Castro SL, Souza-Brito ARM, Durán N 1998. Application of a multi-endpoint cytotoxicity assay to the trypanocidal compounds 2-propen-1-amine derivatives and determination of their acute toxicity. In Vitro Mol Toxicol 11: 153-160.

De Conti R, Santa-Rita RM, de Souza EM, Melo PS, Haun M, De Castro SL, Durán N 1996b. In vitro trypanocidal activities of a novel series of N,N-dimethyl-2-propen-1-amine derivative. $M i$ crobios 85: 83-87.

De Souza EM, Lansiaux A, Bailly C, Wilson, WD Hu, Q, Boykin DW, Batista MM, Araújo-Jorge TC, Soeiro MNC 2004. Phenyl substitution of furamidine markedly potentiates its antiparasitic activity against Trypanosoma cruzi and Leishmania amazonensis. Biochem Pharmacol 68: 593-600.

De Souza EM, Melo G, Boykin DW, Wilson WD, Hu Q, Soeiro MNC 2006a. Tripanocidal activity of the phenyl-substituted analogue of furamidine DB569 against Trypanosoma cruzi infection in vivo. J Antimicrob Chemoth 58: 610-614.

De Souza EM, Menna-Barreto R, Araújo-Jorge TC, Kumar A, Hu Q, Boykin DW, Soeiro MNC 2006b. Antiparasitic activity of aromatic diamidines is related to apoptosis-like death in Trypanosoma cruzi. Parasitology 133: 75-79.

De Souza EM, Oliveira GM, Soeiro MNC 2007. Electrocardiographic findings in acutely and chronically Trypansoma cruzi-infected mice treated by a phenyl-substituted analogue of furamidine DB569. Drug Targets Insights 2: 61-69.

Dias JC 2007. Globalization, inequity and Chagas disease. Cad Saude Publica 23 (Suppl.): S13-22.

Dykstra CC, McClernon DR, Elwell LP, Tidwell RR 1994. Selective inhibition of topoisomerases from Pneumocystis carinii compared with that of topoisomerases from mammalian cells. Antimicrob Agents Chemother 38: 1890-1898.

Goulart MOF, Falkowski P, Ossowski T, Liwo A 2003. Electrochemical study of oxygen interaction with lapachol and its radical anions. Bioelectrochemistry 59: 85-87.

Hegazi AG, Abd-El-Hady FK, Abd-Allah FA 2000. Chemical composition and antimicrobial activity of European propolis. Z Naturforsch 55: 70-75.

Higashi KO, De Castro SL 1994. Propolis extracts are effective against Trypanosoma cruzi and have an impact on its interaction with host cells. J Ethnopharmacol 43: 149-155.

Higuchi ML, Benvenuti LA, Martins-Reis M, Metzger M 2003. Pathophysiology of the heart in Chagas' disease: current status and new developments. Cardiovasc Res 60: 96-107.

Lopes CC, Lopes RSC, Pinto AV, Costa PRR 1984. Efficient synthesis of cytotoxic quinones: 2-Acetyl-4H,9H-naphtho[2,3-b]furan4,9-dione, J Heterocyclic Chem 21: 621-622. 
Lüllmann H, Lüllmann-Rauch R, Wassermann O 1978. Lipidosis induced by amphiphilic cationic drugs. Biochem Pharmacol 27: 1103-1108.

Machado GM, Leon LL, De Castro SL 2007. Activity of Brazilian and Bulgarian propolis against different species of Leishmania. Mem Inst Oswaldo Cruz 102: 73-77.

Marcucci MC 2000. Process to typing natural products. Requested patent. Brazilian National Institute for Intellectual Property INPI, n PI 0105471-6, 22 December.

Marcucci MC, Ferreres F, García-Viguera C, Bankova VS, De Castro SL, Dantas AP, Valente PHM, Paulino N 2001. Phenolic compounds from Brazilian propolis with pharmacological activities. J Ethnopharmacol 74: 105-112.

Marino AP, Silva AA, Santos PV, Pinto LM, Gazinelli RT, Teixeira MM, Lannes-Vieira J 2005. CC-chemokine receptors: a potential therapeutic target for Trypanosoma cruzi-elicited myocarditis. Mem Inst Oswaldo Cruz 100 (Suppl. I): 93-96.

Mathis AM, Bridges AS, Ismail MA, Kumar A, Francesconi I, Anbazhagan M, Hu Q, Tanious FA, Wenzler T, Saulter J, Wilson WD, Brun R, Boykin DW, Tidwell RR, Hall JE 2007. Diphenyl furans and aza analogs: effects of structural modification on in vitro activity, DNA binding, and accumulation and distribution in trypanosomes. Antimicrob Agents Chemother 51: 2801-2810.

Mathis AM, Holman JL, Sturk LM, Ismail MA, Boykin DW, Tidwell RR, Hall JE 2006. Accumulation and intracellular distribution of antitrypanosomal diamidine compounds DB75 and DB820 in African trypanosomes. Antimicrob Agents Chemother 50: 2185-2191.

McCabe RE, Araújo FG, Remington JS 1983. Ketoconazole protects against infection with Trypanosoma cruzi in a murine model. Am J Trop Med Hyg 32: 960-962.

Menna-Barreto RFS, Corrêa JR, Cascabulho CM, Fernandes MC, Pinto AV, Soares MJ, De Castro SL 2009a. Naphthoimidazoles promote different death phenotypes in Trypanosoma cruzi. Parasitology 136: 499-510.

Menna-Barreto RFS, Corrêa JR, Pinto AV, Soares MJ, De Castro SL 2007. Mitochondrial disruption and DNA fragmentation in Trypanosoma cruzi induced by naphthoimidazoles synthesized from B-lapachone. Parasitol Res 101: 895-905.

Menna-Barreto RFS, Gonçalves RLS, Costa M, Silva RSF, Pinto AV, Oliveira MF, De Castro SL 2009b The activity against Trypanosoma cruzi of novel synthetic naphtoquinones is mediated by mitochondrial dysfunction and oxidative stress. Free Rad Biol Med, in press.

Menna-Barreto RFS, Henriques-Pons A, Pinto AV, Morgado-Diaz JA, Soares MJ, De Castro SL 2005. Effect of a $\beta$-lapachone-derived naphthoimidazole on Trypanosoma cruzi: identification of target organelles. J Antimicrob Chemother 56: 1035-1041.

Menna-Barreto RFS, Salomão K, Dantas AP, Santa-Rita RM, Soares MJ, Barbosa HS, De Castro SL 2009c. Different cell death pathways induced by drugs in Trypanosoma cruzi: an ultrastructural study. Micron 40: 157-168.

Monks TJ, Hanslik RP, Cohen GM, Ross D, Graham DG 1992. Quinone chemistry and toxicity. Toxicol Appl Pharmacol 112: 2-16.

Moura KCG, Emery FS, Neves-Pinto C, Pinto MCFR, Dantas AP, Salomão K, De Castro SL, Pinto AV 2001. Synthesis and trypanocidal activity of naphthoquinones isolated from Tabebuia and heterocyclic derivatives: a review from an interdisciplinary study. J Braz Chem Soc 12: 325-338.

Moura KCG, Salomão K, Menna-Barreto RFS, Emery FS, Pinto MCFR, Pinto AV, De Castro SL 2004. Studies on the trypano- cidal activity of semi-synthetic pyran[b-4,3]naphtho[1,2-d]imidazoles from $\beta$-lapachone. Eur J Med Chem 39: 639-645.

Neves-Pinto C, Dantas AP, De Moura KCG, Emery FS, Polequevitch PF, Pinto MCFR, De Castro SL, Pinto AV 2000. Chemical reactivity studies with naphthoquinones from Tabebuia with antitrypanosomal efficacy. Arzneim-Forsch 50: 1120-1128.

Neves-Pinto C, Malta VRS, Pinto MCFR, Santo RHA, De Castro SL, Pinto AV 2002. Trypanocidal phenazine derived from $\beta$-lapachone. J Med Chem 45: 2112-2115.

Nothemberg MS, Takeda GKF, Najjar R 1991. Adducts of nitroimidazole derivatives with Rhodium(II) carboxylates: synthesis, characterization and evaluation of antichagasic activities. J Inorg Biochem 42: 217-229.

Nwaka S, Hudson A 2006. Innovative lead discovery strategies for tropical diseases. Nat Rev Drug Discov 5: 941-955.

O'Brien PJ 1991. Molecular mechanism of quinone cytotoxicity. Chem-Biol Interact 80: 1-41.

Oliveira DA, Pereira DG, Fernandes AMAP, De Castro SL, Souza Brito ARM, De Souza AO, Durán N 2005. Trypanocidal activity of 2-propen-1-amine derivatives on trypomastigotes culture and in animal model. Parasitol Res 95: 161-166.

Olliaro P, Guerin P, Gerstl S, Haaskjold A, Rottingen J, Sundar S 2005. Treatment options for visceral leishmaniasis: a systematic review of clinical studies done in India, 1980-2004. Lancet Infect Dis 5: 763-774.

Pacheco MGO, Silva CF, De Souza EM, Batista MM, Silva PB, Kumar A, Stephens CE, Boykin DW, Soeiro MNC 2009. Trypanosoma cruzi: activity of heterocyclic cationic molecules in vitro. Exp Parasitol, in press.

Park YK, Alencar SM, Aguiar CL 2002. Botanical origin and chemical composition of Brazilian propolis. J Agric Food Chem 50: 2502-2506.

Paulino N, Dantas AP, Bankova VS, Longhi DT, Scremin A, De Castro SL, Calixto JB 2003. Bulgarian propolis induces analgesic and anti-inflammatory effects in mice and inhibits in vitro contraction of airway smooth muscle. J Pharmacol Sci 93: 307-313.

Pereira DG, De Castro SL, Durán N 1998. Activity of N,N-dimethyl2-propen-1-amine derivatives in mice experimentally infected with Trypanosoma cruzi. Acta Trop 69: 205-211.

Pinto AV, Ferreira VF, Pinto MCFR, Mayer LU 1985. Reaction of 2-amino-1,4-naphthoquinone derivatives with dimethyl acetylenedicarboxylate. Synthetic Comm 15: 1181-1189.

Pinto AV, Menna-Barreto RFS, De Castro SL 2007. Naphthoquinones isolated from Tabebuia: a review about the synthesis of heterocyclic derivatives, screeening against Trypanosoma cruzi and correlation structure-trypanocidal activity. Phytomedicines. In: Recent progress in medicinal plants, JN Govil (ed.), vol. 16, Studium Press, Houston, p. 112-127.

Pinto AV, Neves Pinto C, Pinto MCFR, Emery FS, De Moura KCG, Carvalho CEM, Brinn IM 1997a. Fluorescent symmetric phenazines from naphthoquinones. Heterocycles 45: 2431-2436.

Pinto AV, Neves Pinto C, Pinto MCFR, Santa Rita RM, Pezzella C, De Castro SL 1997b. Trypanocidal activity of synthetic heterocyclic derivatives from active quinones from Tabebuia sp. ArzneimForsch 47: 74-79.

Pinto AV, Pinto MCFR, Aguiar MA, Capella RS 1982. Transformações do lapachol em nafto-[1,2-b]-furanaquinonas naturais. $A n$ Acad Bras Cienc 54: 115-118.

Prytzyk E, Dantas AP, Salomão K, De Castro SL, Pereira AS, Bankova VS, Aquino Neto FR 2003. Flavonoids and trypanocidal of Bulgarian propolis. J Ethnopharmacol 88: 189-193. 
Rocha MO, Teixeira MM, Ribeiro AL 2007. An update on the management of Chagas cardiomyopathy. Expert Rev Anti Infect Ther 5: 727-743.

Rosypal AC, Hall JE, Bakunova S, Patrick DA, Bakunov S, Stephens CE, Kumar A, Boykin DW, Tidwell RR 2007. In vitro activity of dicationic compounds against a North American foxhound isolate of Leishmania infantum. Vet Parasitol 145: 207-216.

Rosypal AC, Werbovetz KA, Salem M, Stephens CE, Kumar A, Boykin DW, Hall JE, Tidwell RR 2008. Inhibition by dications of in vitro growth of Leishmania major and Leishmania tropica: causative agents of old world cutaneous leishmaniasis. J Parasitol 94: 743-749.

Salomão K, Dantas AP, Borba CM, Campos LC, Machado DG, Aquino Neto FR, De Castro SL 2004. Chemical composition and microbicidal activity of extracts from Brazilian and Bulgarian propolis. Lett Appl Microbiol 38: 87-92.

Salomão K, Pereira PRSCS, Campos LC, Borba CM, Cabello PH, Marcucci MC, De Castro SL 2008. Brazilian propolis: correlation between chemical composition and microbicidal activity. EvidBased Compl Altern Med 5: 317-324.

Salomão K, Souza EM, Henriques-Pons A, Barbosa HS, de Castro SL 2009. Brazilian green propolis: effects in vitro and in vivo on Trypanosoma cruzi. Evid-Based Compl Altern Med, in press.

Schmunis GA 2007. Epidemiology of Chagas disease in non-endemic countries: the role of international migration. Mem Inst Oswaldo Cruz 102 (Suppl. I): 75-85.

Sepulveda-Boza S, Cassels BK 1996. Plant metabolites active against Trypanosoma cruzi. Planta Med 62: 98-105.

Shapiro TA, Englund PT 1990. Selective cleavage of kinetoplast DNA minicircles promoted by antitrypanosomal drugs. Proc Natl Acad Sci 87: 950-954.

Silva CF, Batista MM, Batista DG, de Souza EM, Silva PB, Oliveira GM, Batista MM, Shareef AR, Boykin DW, Soeiro MNC 2008. In vitro and in vivo studies of the trypanocidal activity of a diarylthiophene diamidine against Trypanosoma cruzi. Antimicrob Agents Chemother 52: 3307-3314.

Silva CF, Batista MM, De Souza EM, Meirelles MNL, Stephens CE, Som P, Boykin DW, Soeiro MNC 2007a. Cellular effects of reversed amidines on Trypanosoma cruzi. Antimicrob Agents Chemother 51: 3803-3809.

Silva CF, Batista MM, Mota RA, De Souza EM, Stephens CE, Som P, Boykin DW, Soeiro MNC 2007b. Activity of "reversed" diamidines against Trypanosoma cruzi in vitro. Biochemical Pharmacol 73: 1939-1946.

Silva Jr EM, Menna-Barreto RFS, Pinto MCFR, Silva RSF, Teixeira DV, Souza MCBV, de Simone CA, De Castro SL, Ferreira VF, Pinto AV 2008a. Naphthoquinoidal [1,2,3]-triazole, a new structural moiety active against Trypanosoma cruzi. Eur J Med Chem 43: $1774-1780$.

Silva Jr EM, Souza MCBV, Fernandes MC, Menna-Barreto RFS, Pinto MCFR, Lopes FA, Simone CA, Andrade CK, Pinto AV, Ferreira VF, De Castro SL 2008b. Synthesis and anti-Trypanosoma cruzi activity of derivatives from nor-lapachones and lapachones. Bioorganic Med Lett 16: 5030-5038.
Silva RSF, Costa EM, Trindade ULT, Teixeira DV, Pinto MCFR, Santos GL, Malta VRS, De Simone CA, Pinto AV, De Castro SL 2006. Synthesis of naphthofuranquinones with activity against Trypanosoma cruzi. Eur J Med Chem 41: 526-530.

Singh G, Dey CS 2007. Induction of apoptosis-like cell death by pentamidine and doxorubicin through differential inhibition of topoisomerase II in arsenite-resistant Leishmania donovani. Acta Trop 103: 172-185.

Soeiro MNC, De Castro SL 2009. Trypanosoma cruzi targets for new chemotherapeutic approaches. Expert Opin Ther Targets 13: $105-121$.

Soeiro MNC, de Castro SL, Souza EM, Batista DGJ, Silva CF, Boykin DW 2008. Diamidines activity upon trypanosomes: the state of the art. Curr Mol Pharmacol 1: 151-161.

Soeiro MNC, De Souza EM, Stephens CE, Boykin DW 2005. Aromatic diamidines as antiparasitic agents. Expert Opin Investig. Drugs 14: 957-972.

Solari A, Saavedra H, Sepulveda C, Oddó D, Acuña G, Labarca J, Muñoz S, Cuny G, Brengues C, Veas F, Bryan RT 1993. Successful treatment of Trypanosoma cruzi encephalitis in a patient with hemophilia and AIDS. Clin Inf Dis 16: 255-259.

Souto-Padron T, Cunha-Silva NL, De Souza W 1993. Acetylated $\alpha$-tubulin in Trypanosoma cruzi: immunocytochemical localization. Mem Inst Oswaldo Cruz 88: 517-528.

Souza AO, Hemerly FP, Busollo AC, Melo PS, Machado GMC, Miranda CC, Santa-Rita RM, Haun M, Leon LL, Sato DN, De Castro SL, Durán N 2002. 3-[4'-bromo-(1,1'-biphenyl)-4-yl]-N,N-dimethyl-3-(2-thienyl)-2-propen-1-amine: synthesis, cytotoxicity, trypanocidal, leishmanicidal and antimycobacterial activities. J Antimicrobial Chemother 50: 629-637.

Souza AO, Hemerly FP, Gomes-Cardoso L, Santa-Rita R, Leon LL, De Castro SL, Duran N 2004. 2-Propen-1-amine derivatives and their synthetic intermediates: activity against pathogenic trypanosomatids. J Chemother 16: 530-533.

Stephens CE, Brun R, Salem MM, Werbovetz KA, Tanious F, Wilson WD, Boykin DW 2003. The activity of diguanidino and "reversed" diamidino 2,5-diarylfurans versus Trypanosoma cruzi and Leishmania donovani. Bioorg Med Chem Lett 13: 2065-2069.

Trusheva B, Popova M, Bankova VS, Simova S, Marcucci MC, Miorin PL, da Rocha Pasin F, Tsvetkova I 2006. Bioactive constituents of Brazilian red propolis. Evid-Based Compl Altern Med 3: $249-254$

Vaidian AK, Weiss LM, Tanowitz HB 2004. Chagas' disease and AIDS. Kinetoplastid Biol Dis 3: 2.

Werbovetz K 2006. Diamidines as antitrypanosomal, antileishmanial and antimalarial agents. Curr Opin Investig Drugs 7: 147-157.

Wilson WD, Tanious FA, Mathis A, Tevis D, Hall JE, Boykin DW 2008. Antiparasitic compounds that target DNA. Biochimie 90: 999-1014.

Winkelmann E, Raether W, Sinharay A 1978. Chemotherapeutically active nitro compounds. 4,5-Nitroimidazoles (Part II). ArzneimForsch 28: 351-366. 